\title{
antibiotics
}

ISSN 2079-6382

www.mdpi.com/journal/antibiotics

Article

\section{Ciprofloxacin Affects Host Cells by Suppressing Expression of the Endogenous Antimicrobial Peptides Cathelicidins and Beta-Defensin-3 in Colon Epithelia}

Protim Sarker ${ }^{1}$, Akhirunnesa Mily ${ }^{1}$, Abdullah Al Mamun ${ }^{1, \dagger}$, Shah Jalal ${ }^{2}$, Peter Bergman ${ }^{2}$, Rubhana Raqib ${ }^{1}$, Gudmundur H. Gudmundsson ${ }^{3}$ and Birgitta Agerberth ${ }^{2, *}$

1 Centre for Vaccine Science, International Centre for Diarrhoeal Disease Research,

Bangladesh (icddr,b), 68 Shaheed Tajuddin Ahmed Sharani, Mohakhali, Dhaka 1212, Bangladesh;

E-Mails: protim@icddrb.org (P.S.); mily@icddrb.org (A.M.);

mamun104@gmail.com (A.A.M.); rubhana@icddrb.org (R.R.)

2 Department of Laboratory Medicine, Division of Clinical Microbiology (F68),

Karolinska University Hospital Huddinge, S-141 86 Stockholm, Sweden;

E-Mails: Shah.Jalal@ki.se (S.J.); Peter.Bergman@ki.se (P.B.)

3 Institute of Biology and Biomedical Center, University of Iceland, 101 Reykjavik, Iceland;

E-Mail: ghrafn@hi.is

$\dagger$ Current address: Department of Environmental Physiology, Shimane University Faculty of

Medicine, Izumo-shi, Shimane 693-8501, Japan.

* Author to whom correspondence should be addressed; E-Mail: Birgitta.Agerberth@ki.se;

Tel.: +46-707-494952; Fax: +46-8-585-87933.

Received: 27 May 2014; in revised form 14 July 2014 / Accepted: 15 July 2014 /

Published: 25 July 2014

Abstract: Antibiotics exert several effects on host cells including regulation of immune components. Antimicrobial peptides (AMPs), e.g., cathelicidins and defensins display multiple functions in innate immunity. In colonic mucosa, cathelicidins are induced by butyrate, a bacterial fermentation product. Here, we investigated the effect of antibiotics on butyrate-induced expression of cathelicidins and beta-defensins in colon epithelial cells. Real-time PCR analysis revealed that ciprofloxacin and clindamycin reduce butyrate-induced transcription of the human cathelicidin LL-37 in the colonic epithelial cell line HT-29. Suppression of LL-37 peptide/protein by ciprofloxacin was confirmed by Western blot analysis. Immunohistochemical analysis demonstrated that ciprofloxacin suppresses the rabbit cathelicidin CAP-18 in rectal epithelia of healthy and butyrate-treated Shigella-infected 
rabbits. Ciprofloxacin also down-regulated butyrate-induced transcription of the human beta-defensin-3 in HT-29 cells. Microarray analysis of HT-29 cells revealed upregulation by butyrate with subsequent down-regulation by ciprofloxacin of additional genes encoding immune factors. Dephosphorylation of histone H3, an epigenetic event provided a possible mechanism of the suppressive effect of ciprofloxacin. Furthermore, LL-37 peptide inhibited Clostridium difficile growth in vitro. In conclusion, ciprofloxacin and clindamycin exert immunomodulatory function by down-regulating AMPs and other immune components in colonic epithelial cells. Suppression of AMPs may contribute to the overgrowth of $C$. difficile, causing antibiotic-associated diarrhea.

Keywords: antibiobic; microbiota; butyrate; histone modifications; host defense peptides; LL-37; innate immunity; impaired immune responses; Clostridium difficile; antibiotic-associated diarrhea

\section{Introduction}

Antimicrobial peptides/proteins (AMPs) are important effectors of the immediate host defense, exerting antimicrobial activity and immunomodulation [1-4]. Defensins and cathelicidins are the two major classes of AMPs in mammals. LL-37 is the sole cathelicidin peptide in human and its orthologs in rabbit, mouse, and rat are CAP-18, mCRAMP and rCRAMP, respectively [5]. LL-37 and its orthologs are cationic, amphipathic, $\alpha$-helical peptides. Defensins are cationic peptides, having a characteristic anti-parallel $\beta$-sheet fold and consist of six conserved cysteine residues forming three disulphide bonds [6,7]. Based on the size and disulfide linkage, defensins are classified into $\alpha-, \beta-$, and $\theta$-defensins. In human, six $\alpha$-defensins, e.g., human neutrophil peptides (HNP)-1 to -4 , human defensins (HD)-5 and -6 , and four $\beta$-defensins, e.g., human $\beta$-defensin (HBD)-1 to -4 have, thus far, been characterized [6,8]. LL-37 and/or HBDs have been implicated in several functions including killing of microorganisms, neutralization of lipopolysaccharide, immune regulation, regulation of normal flora, wound healing, angiogenesis, and anticancer activities [3,5,6,8-14].

LL-37 is expressed in neutophils, monocytes, lymphocytes, mast cells eosinophils, dendritic cells, and epithelial cells of different organs [5,14]. HBDs are predominantly expressed in epithelial cells [8]. The expression of LL-37 and HBDs can be modulated by different stimuli in a cell and tissue specific manner [15]. Butyrate, a bacterial fermentation product in colon, upregulates cathelicidins in colonic epithelial cells of human and rabbit [16,17], and, thus, playing an important role in host-microbes interaction in the colonic mucosa.

Antibiotics, apart from exerting bactericidal/bacteriostatic effects on pathogens, can render pathogens susceptible to the host immune system, such as killing of bacteria by polymorphonuclear neutrophils (PMNs) [18]. On the other hand, by inducing production and release of microbial components, antibiotics may provoke proinflammatory responses in host cells [19]. Numerous antibiotics also have direct modulatory effects on immune functions [20]. Moreover, antibiotic treatment disrupts the normal colonic flora that may allow colonization and secondary infections by enteropathogens such as Clostridium difficile, Clostridium perfringens, Staphylococcus aureus, and Salmonella spp. [21]. 
Alteration of the microbiota also affects immune homeostasis including expression of AMPs, leading to infections such as increasing susceptibility to Listeria monocytogenes [22]. C. difficile is the major cause of antibiotic associated diarrhoea (AAD), accounting for $10 \%-20 \%$ of all AAD cases [21]. Clindamycin, extended-spectrum penicillin, cephalosporin and fluoroquinolones including ciprofloxacin are the major antibiotics implicated in $C$. difficile associated diarrhoea (CDAD) [23].

In this study, we determined the effect of several antibiotics on the constitutive and butyrate-induced expression of cathelicidins in colon epithelial cells in vivo and/or in vitro. Since ciprofloxacin suppressed the butyrate-mediated induction of cathelicidins, we also investigated the influence of ciprofloxacin on the induction of human $\beta$-defensins (HBDs) in vitro. A genome wide microarray analysis was performed in order to profile the expression of co-regulated genes. Histone modifications and phosphorylation of MAP kinases were assessed for potential regulatory mechanisms. Lastly, to evaluate cathelicidin suppression as a causal link to CDAD, the inhibitory effect of human cathelicidin LL-37 on $C$. difficile was investigated.

\section{Results}

2.1. Effect of Antibiotics on Expression of the CAMP Gene Encoding LL-37 in HT-29, a Colonic Epithelial Cell Line

A selection of antibiotics, i.e., ciprofloxacin, clindamycin, ofloxacin, levofloxacin, pivmecillinam, azithromycin, ceftriaxone, ampicillin, and isoniazid were screened by real-time PCR for their effect on the CAMP gene expression in HT-29 cells in the presence or absence of sodium butyrate (NaB). Stimulation of cells with $\mathrm{NaB}$ for $24 \mathrm{~h}$ resulted in a significant increase in CAMP gene expression compared to unstimulated cells $(30-40$ fold, $p<0.001)$. Ciprofloxacin suppressed this induction significantly ( $p<0.05$ with $100 \mu \mathrm{g} / \mathrm{mL}$ ciprofloxacin; $p<0.001$ with 125 and $150 \mu \mathrm{g} / \mathrm{mL}$ ciprofloxacin) in a concentration dependent manner (Figure 1A). Clindamycin also exhibited significant suppression ( $p=0.069,0.016$ and 0.028 with 125,150 and $200 \mu \mathrm{g} / \mathrm{mL}$ clindamycin, respectively), although the degree of suppression was much lower than for ciprofloxacin (Figure 1B). Azithromycin, ofloxacin, and levofloxacin reduced the NaB-induced CAMP gene, but the effect was not significant (Figure 1C-E). Pivmecillinam, ampicillin, ceftriaxone, and isoniazid did not show any effect on the CAMP gene induction (Figure $1 \mathrm{~F}-\mathrm{I}$ ). In the absence of $\mathrm{NaB}$, no antibiotic had any effect on $C A M P$ gene expression (data not shown). Thus, ciprofloxacin and to a lesser extent clindamycin significantly down-regulated NaB-induced CAMP expression, while other antibiotics exhibited no significant effect on the induction. Similar results were obtained, when the cells were stimulated for $48 \mathrm{~h}$ (data not shown). Notably, by trypan blue assay, no effect on cell viability was observed after the stimulation of the cells. 
Figure 1. Effect of antibiotics on $\mathrm{NaB}$-induced expression of the CAMP gene encoding LL-37 in HT-29 cells. HT-29 cells were stimulated for $24 \mathrm{~h}$ with $2 \mathrm{mM} \mathrm{NaB}$ alone or in combination with different concentrations of (A) ciprofloxacin; (B) clindamycin; (C) azithromycin; (D) ofloxacin; (E) levofloxacin; (F) pivmecillinam; (G) ceftriaxone; (H) ampicillin; and (I) isoniazid. RNA was extracted from cells and cDNA prepared, which was used to quantify $C A M P$ gene (LL-37 transcript) expression by real time qPCR. CAMP expression is presented as fold change to control (untreated) cells. Data are given as mean \pm SD of seven replicates. One way ANOVA of original data in case of clindamycin or logtransformed data for other antibiotics was utilized in comparing between different groups. Pair-wise effects between groups were compared by the Holm-Sidak post hoc comparison procedure. $* p<0.05, * * * p<0.001$. NaB: sodium butyrate.
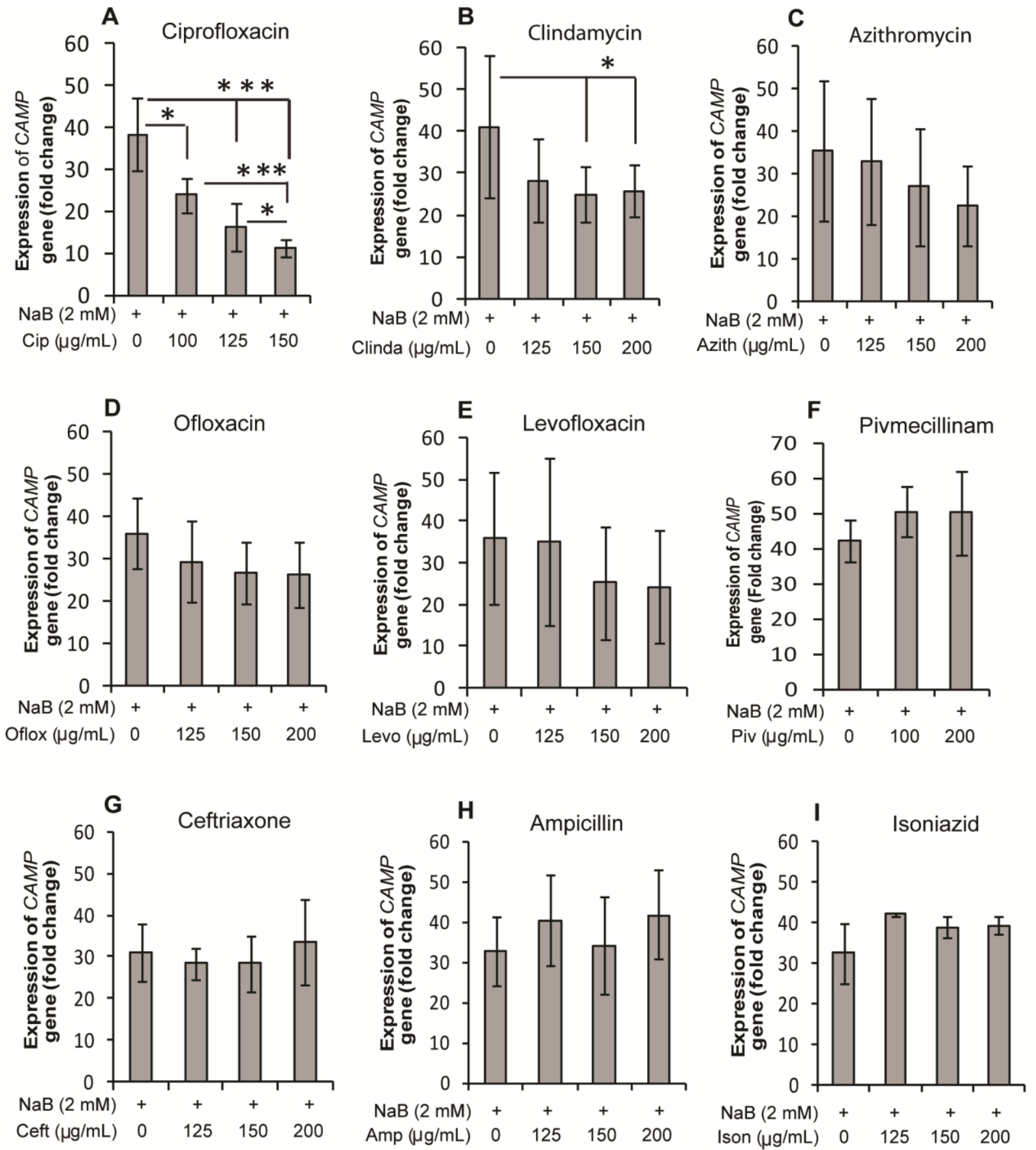
2.2. Effect of Ciprofloxacin and Pivmecillinam on the Expression of LL-37 Peptide and Its Proform hCAP18 in HT-29 Cells

Since a prominent effect of ciprofloxacin was observed on transcriptional level of LL-37 expression, we further investigated the effect on the peptide/protein level by Western blot analysis. The effect of pivmecillinam, a non-responder on CAMP gene expression was also evaluated in parallel. Mature LL-37 peptide $(4.5 \mathrm{kD})$ was either present in low level or not detected in unstimulated culture supernatant of HT-29 cells. However, after stimulation with $\mathrm{NaB}$, the expression was increased and the peptide was clearly detected (Figure 2A,C). Up-regulation of the pro-form hCAP-18 (18 kD) was also observed in the culture supernatants of NaB-stimulated cells compared to unstimulated cells (Figure 2A,C). A dose-dependent down-regulation of NaB-induced expression of hCAP-18 and LL-37 was observed with ciprofloxacin (Figure 2A). Ciprofloxacin alone had no obvious effect on constitutive expression of hCAP-18 or LL-37 (Figure 2B). Pivmecillinam had no detectable effect on constitutive or NaB-induced expression of hCAP-18 or LL-37 (Figure 2C,D). These results clearly demonstrate that ciprofloxacin dose-dependently suppresses LL-37 induction by butyrate at both transcriptional and peptide/protein levels in colon epithelial cells.

Figure 2. Effect of ciprofloxacin and pivmecillinam on LL-37 peptide and hCAP-18 in HT-29 cell supernatants. HT-29 cells were stimulated for $24 \mathrm{~h}$ with $\mathrm{NaB}$ and/or ciprofloxacin $(\mathbf{A}, \mathbf{B})$, with $\mathrm{NaB}$ and/or pivmecillinam; (C,D). Release of LL-37 peptide (lower band) and its proform hCAP-18 (upper band) in culture supernatants was detected by Western blot analysis. Representative pictures are given. Synthetic LL-37 peptide was included as positive control. The blot data in panel $2 \mathrm{~A}$ are composites of two portions of a larger data set, while data of panels $2 \mathrm{~B}$ and $2 \mathrm{D}$ are composites of two experiments. $\mathrm{NaB}$ : sodium butyrate; Cip: ciprofloxacin; Piv: pivmecilinam.
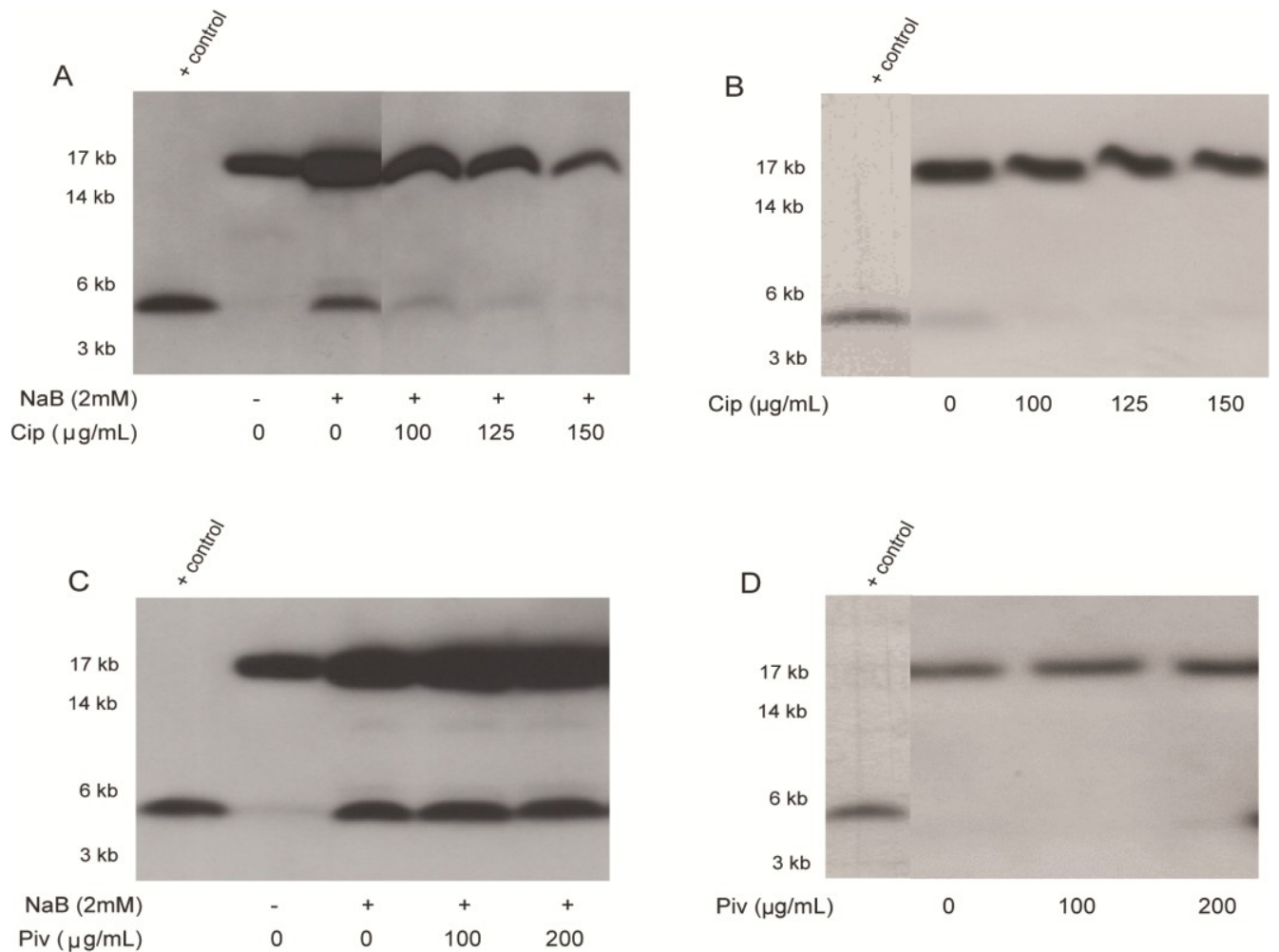


\subsection{In Vivo Effect of Ciprofloxacin and Pivmecillinam on Cathelicidin Expression in Colonic Epithelia}

The physiological relevance of the in vitro effect of ciprofloxacin and pivmecillinam on cathelicidin expression was investigated in healthy rabbits and a rabbit model of shigellosis, representing infectious diarrhoea. Immunohistochemical analysis revealed significant suppression of the rabbit cathelicidin CAP-18 expression in the rectal epithelium of healthy rabbits treated with ciprofloxacin compared to healthy untreated rabbits $(p<0.001)$ (Figure 3A,B). Notable, butyrate is present in the colon and rectum of healthy rabbits. We confirmed results from our previous study [16], demonstrating that CAP-18 expression was significantly down-regulated in rectal epithelium of rabbits infected with Shigella flexneri compared to healthy rabbits $(p<0.001)$ and treatment with $\mathrm{NaB}$ counteracted this down-regulation. Interestingly, when ciprofloxacin was given as adjunct therapy, the induction of CAP-18 was significantly suppressed $(p<0.001)$; the level was even significantly lower than that of infected rabbits $(p<0.001)$ (Figure 3A,B). These data showed that ciprofloxacin has suppressive effect on cathelicidin expression in rectal epithelia of healthy and Shigella-infected rabbits. The NaB-induced reappearance of CAP-18 in rectal epithelium of Shigella-infected rabbits was not affected by pivmecillinam and there was a significant difference between ciprofloxacin treated and pivmecillinam treated rabbits $(p<0.001)$ (Figure 3A,B). Notably, pivmecillinam treatment reduced the expression of CAP-18 to a lesser extent than ciprofloxacin in healthy rabbits $(p<0.01$ between ciprofloxacin treated and pivmecillinam treated healthy rabbits) (Figure 3A,B). Most likely this differential reduction of CAP-18 expression reflects effects of ciprofloxacin on both the normal flora with less butyrate production and direct on epithelial cells, while pivmecillinam only affect the butyrate production mediated by the normal flora.

\subsection{Effect of Ciprofloxacin on the Butyrate-Induced Expression of Human $\beta$-Defensins (HBD)}

\section{Transcripts in HT-29 Cells}

We also examined the effect of ciprofloxacin on NaB-induced expression of $\beta$-defensins. Stimulation of HT-29 cells with NaB resulted in about 10 and 15 fold induction $(p<0.001)$ of the genes encoding HBD-1 and HBD-3, respectively. With the addition of $150 \mu \mathrm{g} / \mathrm{mL}$ ciprofloxacin, the induced expression of HBD-3 was reduced significantly $(p=0.019)$, whereas HBD-1 induction remained unaffected (Figure 4). $\mathrm{NaB}$ did not have any effect on the expression of the gene encoding HBD-2 (data not shown). These results suggest that ciprofloxacin also blocks butyrate-mediated induction of the gene encoding HBD-3 in colonic epithelial cells. 
Figure 3. Effect of ciprofloxacin and pivmecillinam on CAP-18 expression in rectal epithelia of rabbit. Healthy rabbits were either treated with ciprofloxacin $(n=3)$ or pivmecillinam $(n=3)$ or left untreated $(n=3)$. Shigella infected rabbits treated with $2 \mathrm{mM}$ $\mathrm{NaB}$ alone $(n=3)$ or together with ciprofloxacin $(n=3)$ or pivmecillinam $(n=3)$ or left untreated $(n=3)$. Mucosal sections of rectum were stained with the rabbit cathelicidin CAP-18 specific antibody. (A) Representative photomicrographs of CAP-18 immunostaining (arrows). Bars equal to $50 \mu \mathrm{m}$; (B) Semi-quantification of CAP-18 immunostaining are expressed as ACIA score (See materials and methods). Data are given as mean \pm standard deviation. One way ANOVA of log-transformed data was utilized in comparing between different groups. Pair-wise effects between different groups were compared by the Holm-Sidak post hoc comparison procedure. ${ }^{* *} p<0.01$, *** $p<0.001$. NaB: sodium butyrate; Cip: ciprofloxacin; Piv: pivmecilinam.

A

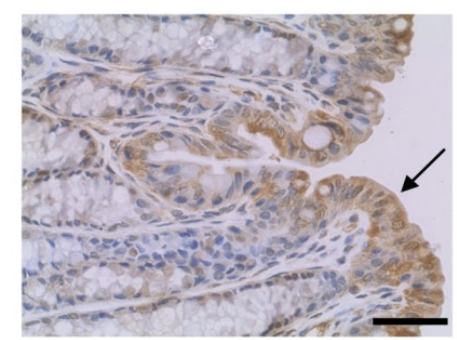

Healthy

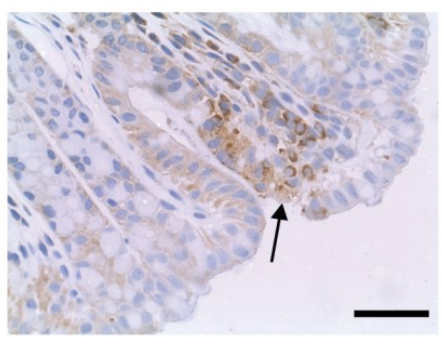

Infected

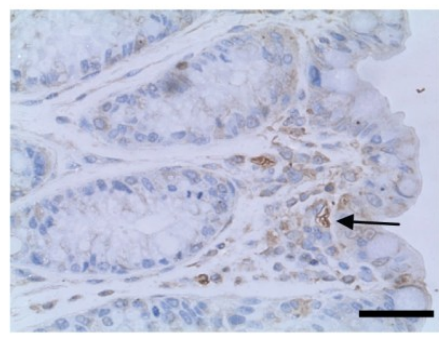

Infected + NaB + Cip

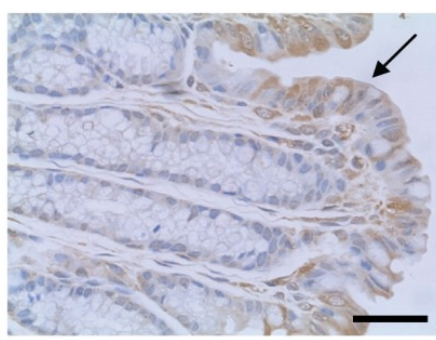

Healthy + Cip

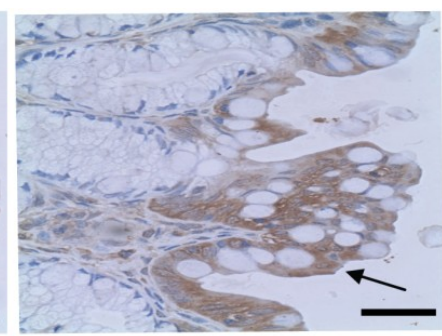

Healthy + Piv

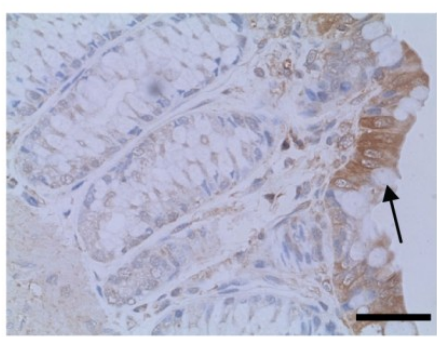

Infected $+\mathrm{NaB}$

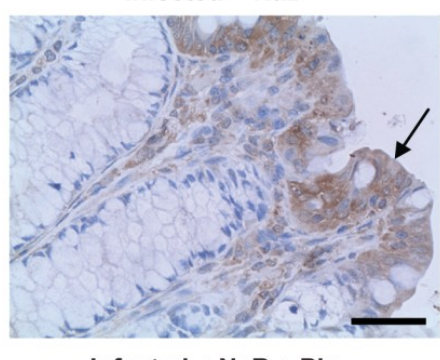

Infected + NaB + Piv
B

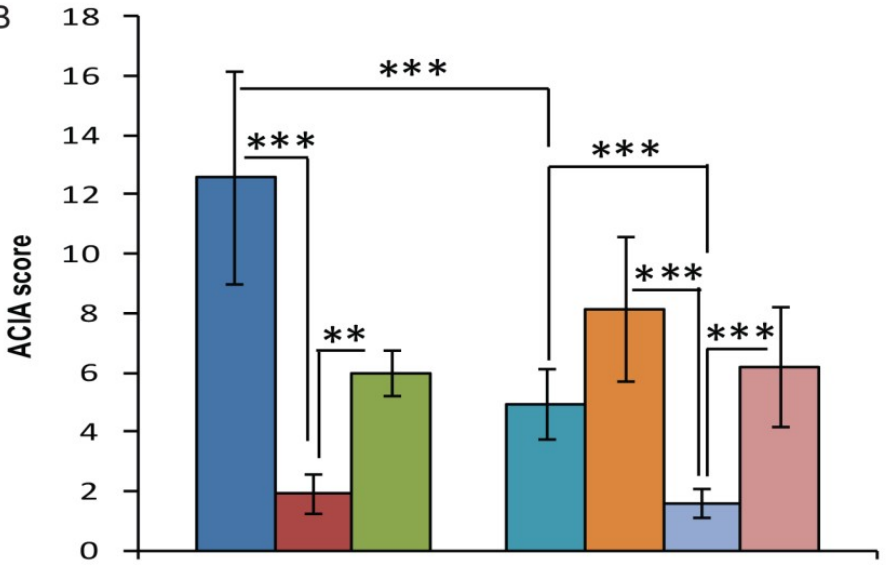

$\square$ Healthy

$\square$ Healthy + Cip

$\square$ Healthy + Piv

$\square$ Infected

$\square$ Infected + NaB

$\square$ Infected + NaB + Cip

$\square$ Infected + NaB + Piv 
Figure 4. Effect of ciprofloxacin on butyrate-induced expression of HBD-1 and HBD-3 transcripts in HT-29 cells. HT-29 cells were stimulated for $24 \mathrm{~h}$ with $2 \mathrm{mM} \mathrm{NaB}$ alone or in combination with $150 \mu \mathrm{g} / \mathrm{mL}$ ciprofloxacin. RNA was extracted from cells and cDNA prepared, which was used to quantify expression of HBD-1 and HBD-3 transcripts by real time $\mathrm{qPCR}$. Gene expression is presented as fold change to control (untreated) cells. Data are given as mean $\pm \mathrm{SD}$ of four replicates. One way ANOVA of log-transformed data was utilized in comparing between different groups. Pair-wise effects between groups were compared by the Holm-Sidak post hoc comparison procedure. ${ }^{*} p<0.05$. $\mathrm{NaB}$ : sodium butyrate; Cip: ciprofloxacin; HBD: human $\beta$-defensin.

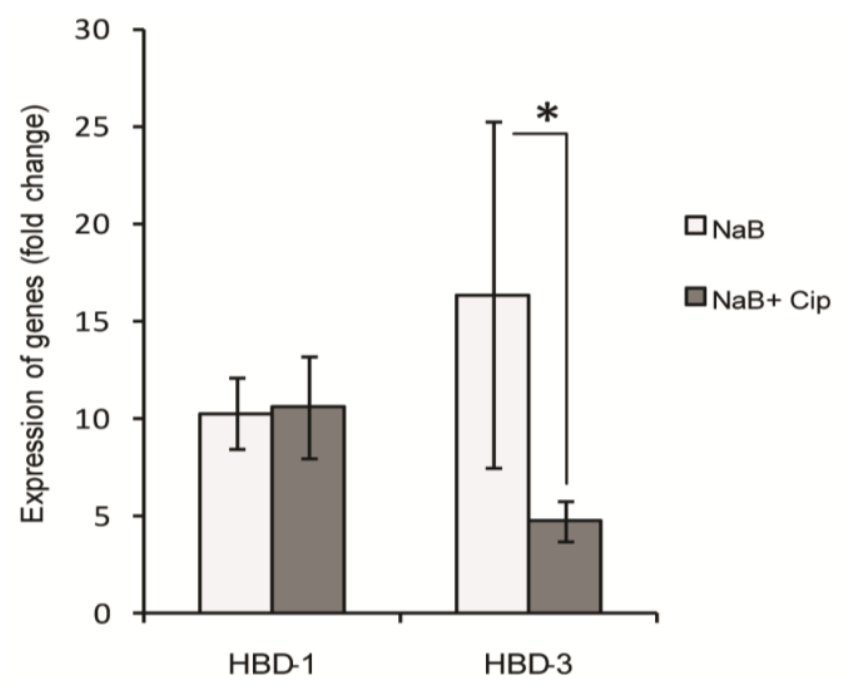

2.5. Suppressive Effect of Ciprofloxacin on Genome-Wide Expression Profile of NaB-Induced Genes in HT-29 Cells

To further investigate the suppressive effect of ciprofloxacin on NaB-induced genes, we performed a microarray analysis on RNA, extracted from HT-29 cells that were stimulated with NaB alone or in combination with ciprofloxacin. The microarray data are deposited in NCBI's Gene Expression Omnibus and are accessible through GEO Series Accession Number GSE45220 [24]. Similar to the CAMP gene, the expression of several immune genes was enhanced in HT-29 cells by $\mathrm{NaB}$ and was subsequently suppressed by ciprofloxacin. Table 1 depicts the most interesting genes from this set that are associated with mucosal immunity including mucins, S100 calcium binding proteins and RNase A. Genes encoding the processing enzyme kallikrein, G protein coupled receptors (GPCR), interleukin receptors, interleukin 18 and nitric oxide synthase were also co-regulated with the $C A M P$ gene (Table 1). The entire list of genes that were co-regulated with the CAMP gene is shown in Supplementary Table S1. 
Table 1. Selected Genes, up-regulated with $\mathrm{NaB}$ treatment and subsequently suppressed with co-administration of ciprofloxacin.

\begin{tabular}{|c|c|c|c|c|c|c|}
\hline \multirow{2}{*}{$\begin{array}{l}\text { Entrez } \\
\text { gene ID }\end{array}$} & \multirow{2}{*}{$\begin{array}{l}\text { Gene } \\
\text { symbol }\end{array}$} & \multirow[t]{2}{*}{ Description } & \multicolumn{2}{|c|}{$\begin{array}{l}\text { Upregulation (NaB } \\
\text { vs. unstimulated) }\end{array}$} & \multicolumn{2}{|c|}{$\begin{array}{c}\text { Downregulation } \\
\text { (NaB + Cip vs. } \\
\mathrm{NaB}) \\
\end{array}$} \\
\hline & & & $\begin{array}{c}\text { Fold } \\
\text { change }\end{array}$ & $p$-value & $\begin{array}{c}\text { Fold } \\
\text { change }\end{array}$ & $p$-value \\
\hline 2840 & GPR17 & G protein-coupled receptor 17 & 4.37 & 0.0002 & -2.93 & 0.0013 \\
\hline 84,873 & GPR128 & $\mathrm{G}$ protein-coupled receptor 128 & 2.7 & 0.0098 & -3.4 & 0.006 \\
\hline 3816 & KLK1 & kallikrein 1 & 2.6 & 0.0012 & -1.99 & 0.014 \\
\hline 6035 & RNASE1 & $\begin{array}{c}\text { ribonuclease, RNase A family, } \\
1 \text { (pancreatic) }\end{array}$ & 8.57 & 0.0011 & -1.91 & 0.042 \\
\hline 6274 & S100A3 & S100 calcium binding protein $\mathrm{A} 3$ & 10.54 & 0.00005 & -3.02 & 0.016 \\
\hline 6271 & S100A1 & S100 calcium binding protein A1 & 7.72 & 0.0073 & -2.47 & 0.027 \\
\hline 57,402 & S100A14 & S100 calcium binding protein A14 & 2.59 & 0.0056 & -1.95 & 0.015 \\
\hline 4846 & NOS3 & nitric oxide synthase 3 (endothelial cell) & 4.05 & 0.0002 & -3.88 & 0.0008 \\
\hline 143,662 & MUC15 & mucin 15 , cell surface associated & 17.2 & 0.03 & -4.7 & 0.05 \\
\hline 394,263 & MUC21 & mucin 21 , cell surface associated & 3.27 & 0.0024 & -2.2 & 0.01 \\
\hline 3606 & IL18 & $\begin{array}{c}\text { interleukin } 18 \\
\text { (interferon-gamma-inducing factor) }\end{array}$ & 2.93 & 0.0013 & -14.3 & 0.0003 \\
\hline 400,935 & IL17REL & interleukin 17 receptor E-like & 2.57 & 0.0052 & -1.96 & 0.011 \\
\hline 3554 & IL1R1 & interleukin 1 receptor, type I & 6.32 & 0.0071 & -3.26 & 0.013 \\
\hline 3557 & IL1RN & interleukin 1 receptor antagonist & 3.4 & 0.02 & -3.2 & 0.04 \\
\hline
\end{tabular}

$\mathrm{NaB}$ : sodium butyrate $(2 \mathrm{mM})$; Cip: ciprofloxacin $(150 \mu \mathrm{g} / \mathrm{mL})$.

\subsection{Epigenetic Modifications are Involved in the Suppressive Effect of Ciprofloxacin in HT-29 Cells}

Butyrate and phenylbutyrate are histone deacetylase inhibitors (HDACi) and have been demonstrated to induce CAMP gene expression [25-27]. To investigate potential epigenetic effects of $\mathrm{NaB}$ and/or ciprofloxacin in HT-29 cells, we evaluated acetylation of histone H3 and H4 by Western blot analysis of histone extracts. Phosphorylation of histone H3 has also been implicated in the induced expression of several genes such as c-fos, c-jun, additional activator protein-1 (AP-1) family genes and c-myc [28]. Hence, phosphorylation of $\mathrm{H} 3$ was also assessed by Western blot analysis of histone extracts. $\mathrm{NaB}$ augmented acetylation of histone $\mathrm{H} 3$ at Lys14, histone $\mathrm{H} 4$ at Lys16 and phosphorylation of histone $\mathrm{H} 3$ at Ser10 within $2 \mathrm{~h}$ of stimulation that lasted up to $24 \mathrm{~h}$ (Figure 5A-D). Ciprofloxacin exhibited no effect on the NaB-induced acetylation of H3 and H4 (Figure 5A,B). Interestingly, ciprofloxacin dose-dependently reduced the induction of phosphorylation of histone $\mathrm{H} 3$ at Ser10 (Figure 5C). Changes of H3 phosphorylation in HT-29 after treatment with NaB alone or in combination with ciprofloxacin was confirmed by the immunofluorescence staining of cells (Figure 5D). Ciprofloxacin alone had no effect on histone phosphorylation and acetylation (data not shown). These findings indicate the involvement of both acetylation and phosphorylation of histones in butyrate-induced genes. However, only phosphorylation of histone H3 was correlated with the ciprofloxacin-mediated down-regulation of butyrate-induced genes. 
Figure 5. Histone modifications in HT-29 cells after treatment with $\mathrm{NaB}$ alone or in combination with ciprofloxacin. HT-29 cells were stimulated for $24 \mathrm{~h}$ with $2 \mathrm{mM} \mathrm{NaB}$ alone or in combination with different concentrations of ciprofloxacin. Histone was extracted from cells and utilized for Western blot analysis to detect (A) acetylation of histone H3 Lys14; (B) acetylation of histone H4 Lys16; (C) phosphorylation of histone H3 Ser10; (D) Phosphorylation of histone $\mathrm{H} 3$ at Ser10 was also detected by immunofluorescence staining of the cells. Arrows indicate examples of positively stained cells. NaB: sodium butyrate; Cip: ciprofloxacin; AcH3(K14): Acetylation of histone $\mathrm{H} 3$ at Lys14; AcH4(K16): Acetylation of histone H4 at Lys16; pH3(S10): Phosphorylation of histone $\mathrm{H} 3$ at Ser10.

A

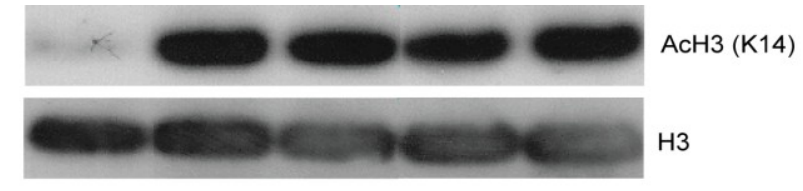

B
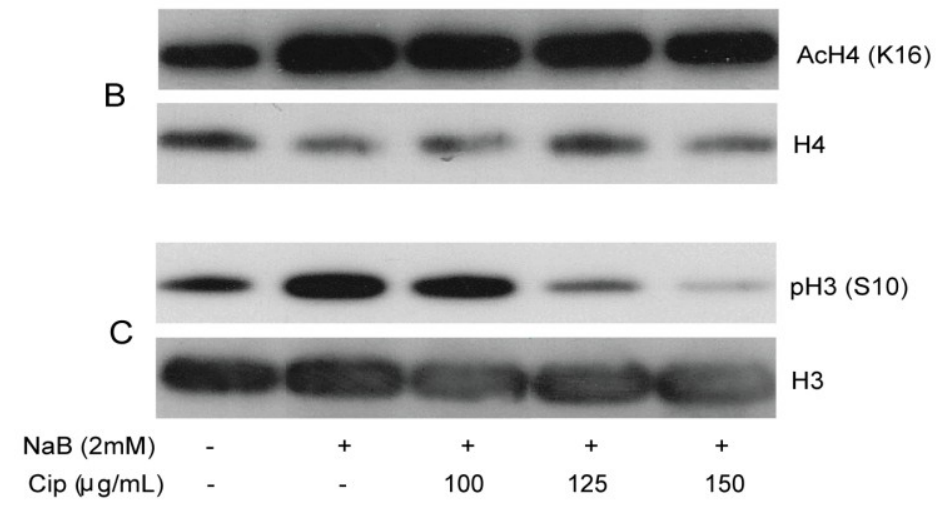

D

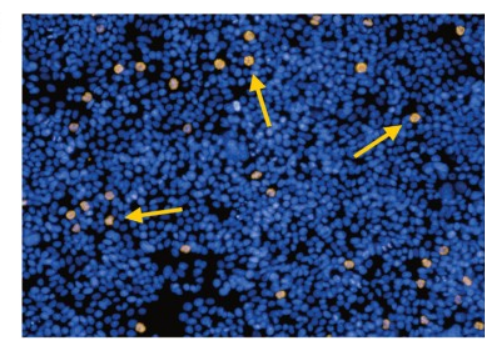

Unstmulated

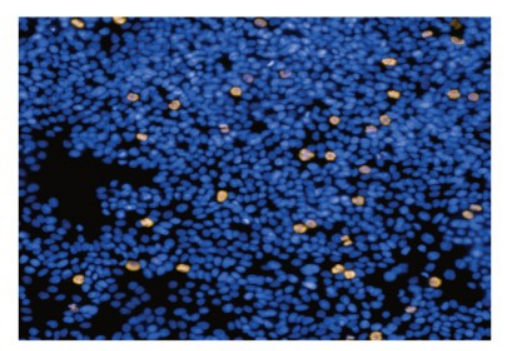

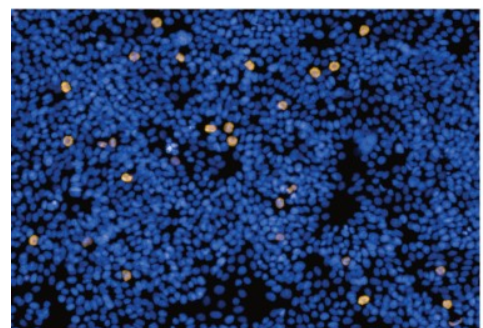

$\mathrm{NaB}+\mathrm{Cip}(100 \mu \mathrm{g} / \mathrm{mL})$

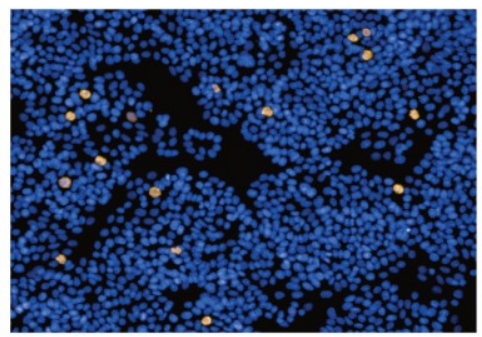

$\mathrm{NaB}+\mathrm{Cip}(125 \mu \mathrm{g} / \mathrm{mL})$
$\mathrm{NaB}$

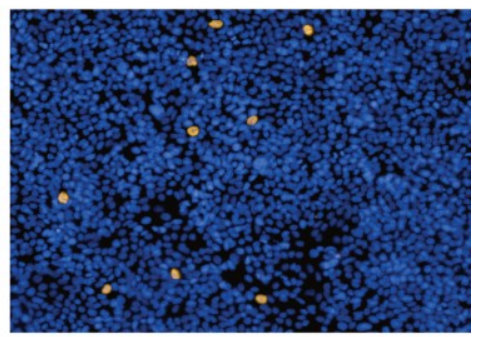

$\mathrm{NaB}+\mathrm{Cip}(150 \mu \mathrm{g} / \mathrm{mL})$

To approach the involvement of MAP kinase signaling pathway, the phosphorylation of ERK and p38 in HT-29 cells was investigated after treatment of the cells with $\mathrm{NaB}$ and/or ciprofloxacin. By Western blot analysis of cell lysates, no differences between treatment groups were observed at any time point starting from $5 \mathrm{~min}$ to $24 \mathrm{~h}$ (data not shown). 


\subsection{In Vitro Effect of Synthetic LL-37 Peptide on C. Difficile}

To investigate if the clinical observation that ciprofloxacin causing overgrowth of $C$. difficile might be associated with inhibitory effect on cathelicidin expression in colonic epithelia, the antibacterial activity of LL-37 against $C$. difficile was evaluated. Incubation of two clinical isolates of ciprofloxacin resistant $C$. difficile with $5 \mu \mathrm{M}$ LL-37 led to four log reduction of colony forming unit (CFU) compared to that obtained by incubating without LL-37 $(p<0.05)$ (Figure 6), showing that LL-37 is able to kill $C$. difficile in vitro.

Figure 6. Inhibitory effect of synthetic LL-37 peptide on clinical isolates of Clostridium difficile. Two clinical isolates of $C$. difficile that were metronidazole and vancomycin sensitive but resistant to ciprofloxacin were treated with or without LL-37 peptide in MHB in wells of microtiter plate. Bacterial suspensions from individual wells were plated on blood-agar for counting of CFU. Lower and upper boundaries of the boxes and the horizontal bars in between indicate 25 th percentile, 75 th percentile and group median, respectively. Vertical lines through the boxes join the minimum and maximum values. Kruskal-Wallis ANOVA on Ranks of original data was utilized in comparing between different groups. Tukey test was used to compare the pair wise effects between treatment groups. ${ }^{*} p<0.05$. CFU: colony forming unit; MHB: Mueller-Hinton broth.

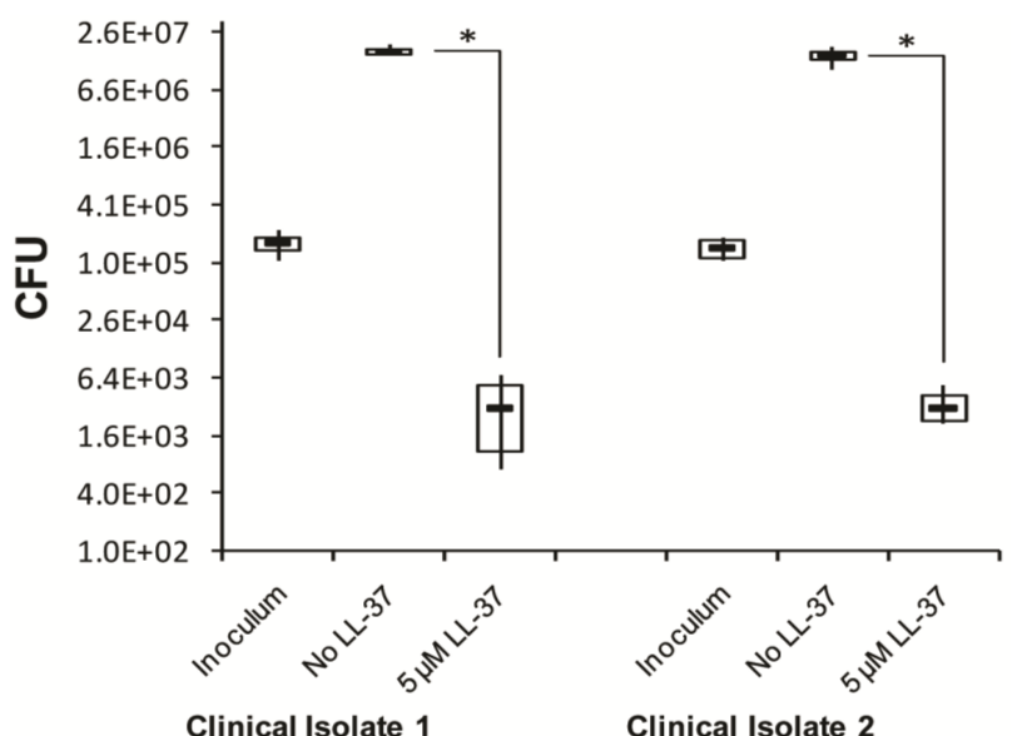

\section{Discussion}

In this study, we demonstrate that ciprofloxacin and clindamycin significantly suppress butyrate-mediated induction of cathelicidin in the colon epithelial cell line HT-29. Suppressed expression of cathelicidin by ciprofloxacin was also observed in vivo in the rectal epithelium of healthy rabbits, where butyrate is present, and butyrate-treated Shigella-infected rabbits. Moreover, ciprofloxacin suppressed butyrate-induced expression of HBD-3 in HT-29 cells. The direct effect of ciprofloxacin in vivo is demonstrated in healthy rabbits by higher suppression of CAP-18 by ciprofloxacin as compared to pivmecillinam. Both antibiotics disrupt the normal flora, leading to reduced butyrate level and lower CAP-18 expression. However, ciprofloxacin exerts additional 
suppression by directly affecting epithelial cells. The induction of the two peptides by butyrate and subsequent reduction by ciprofloxacin is correlated to the phosphorylation status of histone H3 at Ser10. Furthermore, the peptide LL-37 exhibited inhibitory effect on the growth of two ciprofloxacin resistant strains of $C$. difficile in vitro.

Ciprofloxacin, a second generation fluoroquinolone antibiotic, has a broad spectrum bactericidal activity and acts by inhibiting bacterial DNA gyrase/topoisomerase. Several antibiotics including ciprofloxacin and other fluoroquinolones are known to exert modulatory effects on immunity such as down-regulation of proinflammatory cytokines [22,29]. In addition, ciprofloxacin modulates phagocytic and killing capacity of neutrophils and macrophages [30,31], and affects the expression of toll-like receptors, CD14, CD40 and intracellular adhesion molecules in monocytes [32,33]. Furthermore, ciprofloxacin inhibits cytokine-induced nitric oxide production in human colon epithelial cells [34]. Here, we have shown that ciprofloxacin dose-dependently inhibits butyrate-induced expression of the human cathelicidin LL-37 and $\beta$-defensin (HBD)-3 in HT-29 cells. Our study indicates that the general mechanism on gene expression by ciprofloxacin is of epigenetic character through reduced phosphorylation of histone $\mathrm{H} 3$ that may explain the broad effects described for this antibiotic.

We did not detect any effect on LL-37 expression by ciprofloxacin in HT-29 cells in the absence of butyrate. This could be in agreement with previous observations that quinolones only exert immunomodulatory effects in the presence of co-stimulant(s) such as endotoxin, cytokines or stress [32-35]. Butyrate is constantly produced in the large intestine by the fermentation of dietary fibers, which coincides with high expression of CAP-18 and LL-37 in the rectal epithelia of healthy rabbits and humans, respectively (Figure 3 and references [16,36]). This in vivo induced expression of CAP-18 by butyrate in the rectal epithelium of healthy rabbits was also suppressed by ciprofloxacin. In addition, ciprofloxacin inhibited the counteracting effect of butyrate on CAP-18 expression in the rabbit model of shigellosis.

In vitro suppression of LL-37 clearly demonstrates the direct effect of ciprofloxacin on host epithelial cells. It is conceivable that the in vivo reduction of CAP-18 by ciprofloxacin is also a direct effect on rectal epithelial cells, not only an effect caused by killing of the microbiota. On the other hand, pivmecillinam had no suppressive effect on CAP-18 expression in epithelial cells in vitro, but reduced the cathelicidin levels in healthy rabbits, indicating a secondary effect due to less butyrate production by the normal flora.

Ofloxacin and levofloxacin, second and third generation of flouroquinolones, respectively, did not significantly suppress the butyrate-induced LL-37 expression in HT-29 cells. The difference in the degree of suppression might be attributed to structural differences of these fluoroquinolones. Ciprofloxacin possesses a cyclopropyl ring at the quinolone ring, but ofloxacin and levofloxacin lack this ring. Quinolones having cyclopropyl ring were shown to have enhanced anti-leukaemic and haematopoietic effects, as opposed to the quinolones lacking this ring [37,38].

Clindamycin, a lincosamide antibiotic, at higher concentrations than ciprofloxacin significantly suppressed the induction of LL-37 by butyrate in HT-29 cells. In contrast, azithromycin, pivmecillinam, ampicillin, ceftriaxone, and isoniazid exhibited no significant suppression. These results show that the suppressive effect observed is specific for ciprofloxacin and clindamycin, indicating also a direct effect of these antibiotics on host cells and not only mediated by the disturbance of the microbiota composition. 
Numerous additional genes were up-regulated in HT-29 cells after stimulation with NaB as revealed by microarray analysis, emphasizing LL-37 as a marker for mucosal immunity. Interestingly, many of these butyrate-induced genes were down-regulated by ciprofloxacin and are linked to innate immunity, including S100 calcium binding proteins, RNase A, mucins, a cathelicidin processing enzyme (kallikrein) and G protein coupled receptors (GPCR). Calgranulins (S100A8, S100A9 and S100A12) and calprotectin (heterodimer of S100A8 and S100A9) belonging to the family of S100 calcium binding proteins, which exhibit antimicrobial and immunomodulatory properties [39]. Some members of the RNase A superfamily are also involved in host defense [40]. Members of the kallikrein family were shown to process hCAP18 into LL-37 followed by subsequent cleavage to modify the activity of LL-37 in skin [41]. Interestingly, it was recently reported that doxycycline inhibits kallikrein-related peptidases and thus inhibits the generation of active LL-37 [42]. Members of G protein coupled receptors (GPCR) have been shown to mediate the function of short chain fatty acids including butyrate $[43,44]$. GPCR might have interesting implications on butyrate- and/or antibiotics-mediated AMP expression in colonic epithelium. Thus, our results demonstrate a broad effect of ciprofloxacin on the expression of innate immune genes that may promote secondary infections.

Western blot analysis of histone extracts of HT-29 cells revealed a rapid and persistent increase of phosphorylation and acetylation of histone $\mathrm{H} 3$ at Ser10 and Lys14, respectively, after stimulation of cells with $\mathrm{NaB}$. Hyperacetylation was also found at Lys16 of histone H4. Notably, ciprofloxacin, at all time points ( $2 \mathrm{~h}, 4 \mathrm{~h}, 6 \mathrm{~h}$ and $24 \mathrm{~h})$, dose-dependently suppressed the induced phosphorylation of histone H3, which was confirmed by immunofluorescence staining of the cells. However, ciprofloxacin did not affect the induced acetylation of histones. These findings imply epigenetic modifications as part of the ciprofloxacin mediated suppression of butyrate-induced gene expression. We have earlier shown that cyclohexamide, an inhibitor of protein synthesis, blocked the CAMP gene induction by $\mathrm{NaB}$ [27]. Therefore we propose that general histone modification(s) allow expression of genes encoding regulatory proteins for the CAMP gene.

Impaired immune responses have been reported as important factors for CDAD, apart from the disruption of the normal gut flora [45]. Here, we have demonstrated that LL-37 exhibits antibacterial activity against two clinical isolates of $C$. difficile in vitro, which suggests that suppression of AMPs after antibiotic treatment might favor the overgrowth of $C$. difficile. In a recent study, intra-colonic administration of mCRAMP to C. difficile-infected mice improved toxin A-mediated colitis outcome [46]. $\alpha$-defensins were also shown to inhibit the cytotoxic effect of $C$. difficile toxin B [47]. Moreover, in a previous study, down-regulation of the antimicrobial protein RegIII $\gamma$ in the small intestinal mucosa of antibiotic-treated mice was shown to increase the colonization of gut by vancomycin-resistant Enterococcus [48]. These findings indicate that suppression of AMPs may facilitate infection of the gut mucosa by enteropathogens, such as $C$. difficile and resultant disease manifestation. However, C. difficile infection in wild type and $\mathrm{CRAMP}^{-/}$mice demonstrated similar colonic inflammation in both group of mice [46]. Since, mice were pretreated with antibiotic cocktail to induce $C$. difficile infection, it is possible that mCRAMP was down-regulated by the antibiotics in the colonic epithelium of wild type mice, favoring $C$. difficile infection. Moreover, Salzman et al. has shown that enteric defensins regulate the composition of the intestinal flora [12], suggesting a critical role of AMPs in intestinal homeostasis. Hence, by suppressing AMPs, antibiotic treatment of ciprofloxacin or clindamycin may further contribute to alteration of the microbial niche, promoting CDAD. 


\section{Experimental}

\subsection{Ethics Statement}

Experiment in animal model (Research protocol \# 2007-065) was approved by the Animal Experimentation Ethics Committee (AEEC) of the International Centre for Diarrhoeal Disease Research, Bangladesh (icddr,b) on May 07, 2008. All experiments conformed to the rules and guidelines of icddr,b, which was developed based on the recommendations in the Guide for the Care and Use of Laboratory Animals of the National Institutes of Health (NIH). Animal experimentation in this study complied with the "3Rs". REPLACEMENT: Live animals had to be used to evaluate the physiological relevance of the in vitro effect of ciprofloxacin and pivmecillinam on cathelicidin expression. REDUCTION: Minimum numbers of animals were used. REFINEMENT: Rabbits were kept in individual cages and provided with food and water ad libitum. Rabbits were sacrificed within a very short period with an overdose of intravenous sodium pentobarbital (66 mg per $\mathrm{kg}$ body weight). Appropriate veterinary care was taken for assessing and preventing pain and distress by expert veterians of the animal facility.

\subsection{Peptides, Antibodies, Antibiotics and Sodium Butyrate}

Synthetic bioactive peptides LL-37 (LLGDFFRKSKEKIGKEFKRIVQRIKDFLRNLVPRTES) and CAP-18 (GLRKRLRKFRNKIKEKLKKIGQKIQGLLPKLAPRTDY), and affinity-purified chicken anti-CAP-18 antibody were purchased from Innovagen (Lund, Sweden). Monoclonal antiserum against LL-37 was developed in mouse hybridoma cells [49]. Sodium butyrate (NaB), ciprofloxacin, pivmecillinam, ofloxacin, levofloxacin, azithromycin, clindamycin, ampicillin, ceftriaxone and isoniazid were purchased from Sigma-Aldrich (St Louis, MO, USA). Rabbit polyclonal antibodies to phospho-histone H3 (S10) or acetyl-histone H3 (K14) and mouse monoclonal antibodies to histone H3 or H4 were from Abcam (Cambridge, UK). The source of polyclonal antibody to acetyl-histone H4 (K16) was Active Motif (La Hulpe, Belgium). Rabbit polyclonal antibodies to phospho-ERK and phospho-p38 were purchased from Cell signaling technology Inc. (Danvers, MA, USA).

\subsection{Cell Line and Growth Conditions}

HT-29 (ATCC, HTB-38), a human colonic epithelial cell line, was maintained in RPMI-1640 supplemented with 10\% fetal calf serum (FCS), $25 \mathrm{mM}$ HEPES, $2 \mathrm{mM}$ L-glutamine and penicillin-streptomycin (PEST) (Life Technologies, New York, NY, USA) at $37{ }^{\circ} \mathrm{C}$ in $5 \% \mathrm{CO}_{2}$.

\subsection{Primers}

The sequences of the primers for real time qPCR were: CAMP (LL-37 transcript), forward 5'-TCACCAGAGGATTGTGACTTCAAC-3' and reverse 5'-TGAGGGTCACTGTCCCCATAC-3'; human $\beta$-defensin (HBD) - 1 transcript, forward 5'-ATGGCCTCAGGTGGTAACTTTC-3' and reverse 5'-CACTTGGCCTTCCCTCTGTAAC-3'; HBD-2 transcript, forward 5'-GCCTCTTCCAGGTGTTTTTG-3' and reverse 5'-GAGACCACAGGTGCCAATTT-3'; HBD-3 transcript, forward 5'-GCTGCCTTCCAA AGGAGGA-3' and reverse 5'-TTCTTCGGCAGCATTTTCG-3'. 


\subsection{Bacterial Strains}

A clinical isolate of Shigella flexneri 2a, isolated from patient's stool at Dhaka Hospital of icddr,b was used to infect rabbits [16]. For the in vitro killing assay, two strains of Clostridium difficile, isolated from patients stool at Karolinska University Hospital, Huddinge, Stockholm, Sweden were used. These two clinical isolates of $C$. difficile were metronidazole and vancomycin sensitive but resistant to ciprofloxacin. All these bacterial strains were isolated from routine clinical stool samples and these clinical isolates are anonymous.

\subsection{Stimulation of Cells}

HT-29 Cells, grown up to $80 \%-90 \%$ confluence in tissue culture plates (Corning, Steuben County, $\mathrm{NY}$, USA), were stimulated with $2 \mathrm{mM} \mathrm{NaB}$ and/or with different concentrations of several antibiotics for 24 or $48 \mathrm{~h}$. Stimulations were performed in culture medium in the absence of FCS and PEST. Cells incubated with only culture medium served as negative control. The viability of cells was checked by trypan blue assay. To enrich peptides/proteins in culture supernatants, trifluoroacetic acid (TFA) was added to supernatants and were applied to acetonitrile (AcN)-activated OASIS cartridges (Waters, Milford, MA, USA) equilibrated in aqueous $0.1 \%$ TFA. Bound peptides/proteins were eluted with $80 \%$ aqueous AcN in $0.1 \%$ TFA and lyophilized. RNA was extracted from cells utilizing RNeasy RNA purification kit according to the manufacturer's instruction (Qiagen GmbH, Hilden, Germany). Corresponding cDNA was synthesized using a reverse transcriptase kit (Biorad Laboratories Inc., Berkeley, CA, USA).

\subsection{Real-Time RT-PCR}

cDNA samples from HT-29 cells were used to measure the level of the CAMP gene and genes encoding HBD-1, HBD-2, or HBD-3 relative to the housekeeping gene 18S rRNA. Measurements were performed by SYBRGreen based real-time quantitative RT-PCR, using a CFX-96 real time system instrument (Biorad). Results were expressed as fold changes in the treated cells compared to control cells.

\subsection{Microarray Analysis}

Quality and integrity of RNA from HT-29 cells were assessed using the Agilent Bioanalyzer 2100 (Agilent Technologies, Santa Clara, CA, USA). Individual samples were hybridized to Affymetrix Human Gene 1.1 ST arrays. The arrays were scanned using the GeneTitan scanner. Probe cell intensity (CEL) files were preprocessed in Affymetrix Expression Console (EC, version 1.1; Santa Clara, CA, USA) using the following methods; (i) summarization: Probe Logarithmic Intensity Error (PLIER); (ii) background correction: Perfect Match probes-Guanine, Cytosine composition-based background correction (PM-GCBG); (iii) normalization: Global Median. Expression levels between control and treatment groups and between treatment groups were compared using two-tailed, Student's $t$-test. 


\subsection{Cell Lysis and Histone Extraction}

Stimulated/unstimulated HT-29 cells were lysed with RIPA buffer (Sigma-Aldrich). After centrifugation at $13,000 \mathrm{rpm}$ for $10 \mathrm{~min}$ at $4{ }^{\circ} \mathrm{C}$, cell lysates were collected and the remaining cell pellets were used for histone extraction following the method of Lee et al. with some modifications [50]. Briefly, cell pellets were washed twice with PBS and resuspended in ice-cold $0.4 \mathrm{M} \mathrm{H}_{2} \mathrm{SO}_{4}$. Pellets were broken down with brief sonication and incubated overnight on a shaker at $4{ }^{\circ} \mathrm{C}$. After centrifugation at $13,000 \mathrm{rpm}$ for $1 \mathrm{~h}$ at $4{ }^{\circ} \mathrm{C}$, supernatants were collected and histones were precipitated with ice-cold acetone overnight at $-20{ }^{\circ} \mathrm{C}$. The resulting translucent pellets of histones after centrifugation at $13,000 \mathrm{rpm}$ for $10 \mathrm{~min}$ at $4{ }^{\circ} \mathrm{C}$ were air dried, resuspended in ice-cold water and used for Western blot analysis.

\subsection{Western Blot Analysis}

Discontinuous sodium dodecylsulfate-polyacrylamide gel electrophoresis (SDS-PAGE), employing 4\%-12\% NuPAGE Ready Gels (Life Technologies) followed by Western blot analysis were utilized for detection of LL-37 in cell culture supernatants, phosphorylation of ERK and p38 in cell lysates, and phosphorylation/acetylation of histones in histone extracts. After electrophoretic separation, materials in the gel were blotted onto polyvinyldifluoride (PVDF) membrane (Life Technologies) by electrophoretic transfer. Immunoreactivity was detected by subsequent incubation of the membrane with specific primary antibodies and corresponding secondary antibodies conjugated with horseradish peroxidase (Jackson Immunoresearch Laboratories Inc., West Grove, PA, USA). The enhanced chemiluminescence (ECL) Western blotting detection system (GE Healthcare UK Ltd., Buckinghamshire, UK) was utilized to visualize protein/peptide bands.

\subsection{Immunofluorescence Staining of Phosphorylated Histone H3 at Ser10}

HT-29 cells were stimulated with $\mathrm{NaB}$ and/or ciprofloxacin in 96 well tissue culture imaging plate (BD Biosciences, Woburn, MA, USA). Cells were fixed with 2\% paraformaldehyde followed by permeabilization with $0.1 \%$ triton-X-100 (ICN Biomedicals, Solon, OH, USA). Cells were then subsequently incubated with rabbit polyclonal antibody for phospho-histone H3 (S10) and anti-rabbit antibody conjugated with AlexaFluor 594 (Life Technologies). DAPI, a nuclear die, was added to the cells and immunofluorescence staining was detected in an Operetta image analyzer (Perkin Elmer Inc., Alameda, CA, USA).

\subsection{Rabbit Model}

Inbred New Zealand white rabbits (Charles River Laboratories, Wilmington, MA, USA) of either sex, aged between 2.5-3 months and weighing 1.8-1.9 $\mathrm{kg}$ were maintained in the animal resource facilities of icddr,b. Healthy rabbits, free of enteric pathogens (e.g., Salmonella, Shigella, and Vibrio cholera) and coccidia were studied. Twelve rabbits were infected with Shigella flexneri 2a preceded by $36 \mathrm{~h}$ of starvation. Bacterial suspension $\left[10^{9} \mathrm{CFU}\right.$ in $7 \mathrm{ml}$ of normal saline $(0.9 \% \mathrm{wt} / \mathrm{vol}$, $\mathrm{pH}$ 7.2)] was given via sterile orogastric feeding tube to each rabbit. Rabbits developed dysentery within $24 \mathrm{~h}$ of bacterial inoculation. The infected rabbits were orally treated with $\mathrm{NaB}(0.14 \mathrm{mmol} / \mathrm{kg}$ 
body weight/dose) $(n=3)$, or $\mathrm{NaB}$ in combination with ciprofloxacin/pivmecillinam $(20 \mathrm{mg} / \mathrm{kg}$ body weight/dose) ( $n=3$ per antibiotic group) in $20 \mathrm{mM}$ sodium chloride ( $\mathrm{pH}$ 7.2) by utilizing sterile feeding tubes. The treatments were given twice daily (at around 10 am and $4 \mathrm{pm}$ ) for three consecutive days. The remaining three infected rabbits were kept untreated. Healthy rabbits were either treated with ciprofloxacin $(n=3)$ or pivmecillinam $(n=3)$ or left untreated $(n=3)$. When the treatment regime was over, all rabbits were sacrificed with an overdose of intravenous sodium pentobarbital $(66 \mathrm{mg} / \mathrm{kg}$ body weight) (Sigma-Aldrich). The abdomen of each sacrificed rabbit was opened and sections of rectum were collected in $10 \%$ buffered formalin and utilized for immunohistochemical evaluation.

\subsection{In Situ Immunohistochemical Staining and Quantification of CAP-18 Peptide/Protein Expression in Rectal Mucosa of Rabbits}

Formalin fixed tissue pieces of rectum were embedded in paraffin and cut into three micron thick sections. Sections were deparaffinized, and stained with CAP-18 antibody $(6.8 \mu \mathrm{g} / \mathrm{mL})$ and corresponding secondary antibody. Immunohistochemical staining of CAP-18 was analyzed by using a microscope (Leica Microsystems GmbH, Wetzlar, Germany) and the image analysis system Quantimate Q550 (Leica). CAP-18 staining were quantified in the epithelial areas in each tissue section and the results were given as ACIA (Acquired Computerized Image Analysis) score, i.e., total positively stained area $\mathrm{x}$ total mean intensity (1-256 levels per pixel) of the positive area divided by total cell area [51].

\subsection{In Vitro Bacterial Killing}

LL-37 peptide $(5 \mu \mathrm{M})$ was added to the isolates (see under bacterial strains) of $C$. difficile $\left(10^{5} \mathrm{CFU}\right)$ in Mueller-Hinton broth (MHB; Becton Dickinson, NJ, USA) in wells of microtiter plate (Nunc, Thermo Fisher Scientific, NY, USA) in a final volume of $200 \mu \mathrm{L}$. Control wells contained MHB alone and bacteria in MHB without LL-37. The plate was incubated for $48 \mathrm{~h}$ in an anaerobic jar at $37{ }^{\circ} \mathrm{C}$. Bacterial suspension/media from individual wells were plated on blood-agar for counting of CFU.

\subsection{Statistical Analyses}

Statistical analyses were performed by using Sigma STAT for Windows version 3.1 and SPSS. Data were expressed as mean \pm standard deviation or median with 25 th and 75 th percentiles. One way ANOVA was utilized in comparing effects between treatment groups. Data that were not normally distributed and/or failed the equal variance test were log transformed before ANOVA analysis. When significant effect was found between treatment groups, the pair-wise effects between treatment groups were compared by the Holm-Sidak post hoc comparison procedure. If the normality and/or equal variance test failed even after log-transformation, original data were analyzed by Kruskal-Wallis ANOVA on Ranks. After getting significant effect between treatment groups, the Tukey test was used to compare the pair-wise effects between treatment groups. Probabilities were regarded as significant when $p<0.05$. 


\section{Conclusions}

Our study shows that ciprofloxacin and clindamycin significantly downregulate butyrate-mediated induction of innate immune components in the large intestinal epithelia. The prevailing explanation for CDAD pathogenesis is that antibiotic treatment disturbs the normal flora. Here, we demonstrate that the antibiotic-mediated suppression of innate immune effectors might also contribute to CDAD.

\section{Acknowledgments}

This work was supported by "the Swedish Agency for Research Cooperation with developing Countries (Sida, Project No: 0954-93016)"; "The Swedish Research Council, (Grant 58X-11217-14-3)"; "Swedish Cancer Society" (CAN2011/559); "The Swedish Strategic Foundation (SSF)" (RBd08-0014); "Karolinska Institutet"; "Karolinska Institutet Faculty Fund", "The Icelandic Centre for Research (RANNIS)", and "University of Iceland research fund". GHG is a visiting scientist at Karolinska Institutet supported by "The Wenner-Gren Foundations". icddr,b is thankful to the Governments of Australia, Bangladesh, Canada, Sweden and the UK for providing core/unrestricted support.

We acknowledge the staff of the animal facility of icddr,b for their support in doing the animal experimentation. We thank Kristmundur Sigmundsson, the Laboratories for Chemical Biology at Karolinska Institutet (LCBKI), Sweden for assisting us in analyzing the immunofluorescence staining in the Operetta image analyzer. We also acknowledge Bioinformatics and Expression Analysis core facility (BEA), Karolinska Institutet, Sweden for performing the Microarray analysis.

\section{Author Contributions}

P.S., S.J., P.B., R.R., G.H.G. and B.A. conceived and designed the experiments. P.S., A.M. and A.A.M. performed the laboratory experiments. P.S. carried out the statistical analyses. R.R. and B.A. supplied reagents/materials/analysis tools. P.S., G.H.G. and B.A. drafted the manuscript. S.J., P.B. and R.R. revised the manuscript. All authors approved the final version of the manuscript before the submission.

\section{Conflicts of Interest}

The authors declare no conflict of interest.

\section{References}

1. Gottler, L.M.; Ramamoorthy, A. Structure, membrane orientation, mechanism, and function of pexiganan-A highly potent antimicrobial peptide designed from magainin. Biochim. Biophys. Acta 2009, 1788, 1680-1686.

2. Hilchie, A.L.; Wuerth, K.; Hancock, R.E. Immune modulation by multifaceted cationic host defense (antimicrobial) peptides. Nat. Chem. Biol. 2013, 9, 761-768.

3. Hoskin, D.W.; Ramamoorthy, A. Studies on anticancer activities of antimicrobial peptides. Biochim. Biophys. Acta 2008, 1778, 357-375. 
4. Zasloff, M. Antimicrobial peptides of multicellular organisms. Nature 2002, 415, 389-395.

5. Durr, U.H.; Sudheendra, U.S.; Ramamoorthy, A. LL-37, the only human member of the cathelicidin family of antimicrobial peptides. Biochim. Biophys. Acta 2006, 1758, 1408-1425.

6. Dhople, V.; Krukemeyer, A.; Ramamoorthy, A. The human beta-defensin-3, an antibacterial peptide with multiple biological functions. Biochim. Biophys. Acta 2006, 1758, 1499-1512.

7. Selsted, M.E.; Ouellette, A.J. Mammalian defensins in the antimicrobial immune response. Nat. Immunol. 2005, 6, 551-557.

8. Jarczak, J.; Kosciuczuk, E.M.; Lisowski, P.; Strzalkowska, N.; Jozwik, A.; Horbanczuk, J.; Krzyzewski, J.; Zwierzchowski, L.; Bagnicka, E. Defensins: Natural component of human innate immunity. Human Immunol. 2013, 74, 1069-1079.

9. Baroni, A.; Donnarumma, G.; Paoletti, I.; Longanesi-Cattani, I.; Bifulco, K.; Tufano, M.A.; Carriero, M.V. Antimicrobial human beta-defensin-2 stimulates migration, proliferation and tube formation of human umbilical vein endothelial cells. Peptides 2009, 30, 267-272.

10. Kai-Larsen, Y.; Agerberth, B. The role of the multifunctional peptide LL-37 in host defense. Front. Biosci. 2008, 13, 3760-3767.

11. Koczulla, R.; von Degenfeld, G.; Kupatt, C.; Krotz, F.; Zahler, S.; Gloe, T.; Issbrucker, K.; Unterberger, P.; Zaiou, M.; Lebherz, C.; et al. An angiogenic role for the human peptide antibiotic LL-37/hCAP-18. J. Clin. Invest. 2003, 111, 1665-1672.

12. Salzman, N.H.; Hung, K.; Haribhai, D.; Chu, H.; Karlsson-Sjoberg, J.; Amir, E.; Teggatz, P.; Barman, M.; Hayward, M.; Eastwood, D.; et al. Enteric defensins are essential regulators of intestinal microbial ecology. Nat. Immunol. 2010, 11, 76-83.

13. Shaykhiev, R.; Beisswenger, C.; Kandler, K.; Senske, J.; Puchner, A.; Damm, T.; Behr, J.; Bals, R. Human endogenous antibiotic LL-37 stimulates airway epithelial cell proliferation and wound closure. Am. J. Physiol. Lung. Cell. Mol. Physiol. 2005, 289, L842-L848.

14. Vandamme, D.; Landuyt, B.; Luyten, W.; Schoofs, L. A comprehensive summary of LL-37, the factotum human cathelicidin peptide. Cell. Immunol. 2012, 280, 22-35.

15. Schauber, J.; Dorschner, R.A.; Yamasaki, K.; Brouha, B.; Gallo, R.L. Control of the innate epithelial antimicrobial response is cell-type specific and dependent on relevant microenvironmental stimuli. Immunology 2006, 118, 509-519.

16. Raqib, R.; Sarker, P.; Bergman, P.; Ara, G.; Lindh, M.; Sack, D.A.; Nasirul Islam, K.M.; Gudmundsson, G.H.; Andersson, J.; Agerberth, B. Improved outcome in shigellosis associated with butyrate induction of an endogenous peptide antibiotic. Proc. Natl. Acad. Sci. USA 2006, 103, 9178-9183.

17. Schauber, J.; Svanholm, C.; Termen, S.; Iffland, K.; Menzel, T.; Scheppach, W.; Melcher, R.; Agerberth, B.; Luhrs, H.; Gudmundsson, G.H. Expression of the cathelicidin LL-37 is modulated by short chain fatty acids in colonocytes: Relevance of signalling pathways. Gut 2003, 52, 735-741.

18. Mandell, L.A.; Afnan, M. Mechanisms of interaction among subinhibitory concentrations of antibiotics, human polymorphonuclear neutrophils, and gram-negative bacilli. Antimicrob. Agents Chemother. 1991, 35, 1291-1297. 
19. Nau, R.; Eiffert, H. Modulation of release of proinflammatory bacterial compounds by antibacterials: Potential impact on course of inflammation and outcome in sepsis and meningitis. Clin. Microbiol. Rev. 2002, 15, 95-110.

20. Tauber, S.C.; Nau, R. Immunomodulatory properties of antibiotics. Curr. Mol. Pharmacol. 2008, $1,68-79$.

21. Bartlett, J.G. Clinical practice. Antibiotic-associated diarrhea. N. Engl. J. Med. 2002, 346, 334-339.

22. Ubeda, C.; Pamer, E.G. Antibiotics, microbiota, and immune defense. Trends Immunol. 2012, 33, 459-466.

23. Blondeau, J.M. What have we learned about antimicrobial use and the risks for Clostridium difficile-associated diarrhoea? J. Antimicrob. Chemother. 2009, 63, 238-242.

24. Expression data from HT-29, a human colonic epithelial cell line. Available online: http://www.ncbi.nlm.nih.gov/geo/query/acc.cgi?acc=GSE45220 (accessed on 16 March 2013).

25. Kida, Y.; Shimizu, T.; Kuwano, K. Sodium butyrate up-regulates cathelicidin gene expression via activator protein-1 and histone acetylation at the promoter region in a human lung epithelial cell line, EBC-1. Mol. Immunol. 2006, 43, 1972-1981.

26. Schauber, J.; Iffland, K.; Frisch, S.; Kudlich, T.; Schmausser, B.; Eck, M.; Menzel, T.; Gostner, A.; Luhrs, H.; Scheppach, W. Histone-deacetylase inhibitors induce the cathelicidin LL-37 in gastrointestinal cells. Mol. Immunol. 2004, 41, 847-854.

27. Steinmann, J.; Halldorsson, S.; Agerberth, B.; Gudmundsson, G.H. Phenylbutyrate induces antimicrobial peptide expression. Antimicrob. Agents Chemother. 2009, 53, 5127-5133.

28. Bode, A.M.; Dong, Z. Inducible covalent posttranslational modification of histone H3. Sci. STKE 2005, 2005, re4.

29. Dalhoff, A. Immunomodulatory activities of fluoroquinolones. Infection 2005, 33, 55-70.

30. Cacchillo, D.A.; Walters, J.D. Effect of ciprofloxacin on killing of Actinobacillus actinomycetemcomitans by polymorphonuclear leukocytes. Antimicrob. Agents Chemother. 2002, 46, 1980-1984.

31. Wong, J.P.; Schnell, G.; Simpson, M.; Saravolac, E. Effects of liposome-encapsulated ciprofloxacin on phagocytosis, nitric oxide and intracellular killing of Staphylcoccus aureus by murine macrophages. Artif. Cells Blood Substit. Immobil. Biotechnol. 2000, 28, 415-428.

32. Kaji, M.; Tanaka, J.; Sugita, J.; Kato, N.; Ibata, M.; Shono, Y.; Ohta, S.; Kondo, T.; Asaka, M.; Imamura, M. Ciprofloxacin inhibits lipopolysaccharide-induced toll-like receptor-4 and 8 expression on human monocytes derived from adult and cord blood. Ann. Hematol. 2008, 87, 229-231.

33. Katsuno, G.; Takahashi, H.K.; Iwagaki, H.; Sugita, S.; Mori, S.; Saito, S.; Yoshino, T.; Nishibori, M.; Tanaka, N. The effect of ciprofloxacin on CD14 and toll-like receptor-4 expression on human monocytes. Shock 2006, 25, 247-253.

34. Kolios, G.; Manousou, P.; Bourikas, L.; Notas, G.; Tsagarakis, N.; Mouzas, I.; Kouroumalis, E. Ciprofloxacin inhibits cytokine-induced nitric oxide production in human colonic epithelium. Eur. J. Clin. Invest. 2006, 36, 720-729. 
35. Dalhoff, A.; Shalit, I. Immunomodulatory effects of quinolones. Lancet Infect. Dis. 2003, 3, 359-371.

36. Islam, D.; Bandholtz, L.; Nilsson, J.; Wigzell, H.; Christensson, B.; Agerberth, B.; Gudmundsson, G. Downregulation of bactericidal peptides in enteric infections: A novel immune escape mechanism with bacterial DNA as a potential regulator. Nat. Med. 2001, 7, 180-185.

37. Shalit, I.; Kletter, Y.; Weiss, K.; Gruss, T.; Fabian, I. Enhanced hematopoiesis in sublethally irradiated mice treated with various quinolones. Eur. J. Haematol. 1997, 58, 92-98.

38. Yamashita, Y.; Ashizawa, T.; Morimoto, M.; Hosomi, J.; Nakano, H. Antitumor quinolones with mammalian topoisomerase II mediated DNA cleavage activity. Cancer Res. 1992, 52, 2818-2822.

39. Hsu, K.; Champaiboon, C.; Guenther, B.D.; Sorenson, B.S.; Khammanivong, A.; Ross, K.F.; Geczy, C.L.; Herzberg, M.C. Anti-Infective Protective Properties of S100 Calgranulins. Antiinflamm. Antiallergy Agents Med. Chem. 2009, 8, 290-305.

40. Dyer, K.D.; Rosenberg, H.F. The RNase a superfamily: Generation of diversity and innate host defense. Mol. Divers. 2006, 10, 585-597.

41. Yamasaki, K.; Schauber, J.; Coda, A.; Lin, H.; Dorschner, R.A.; Schechter, N.M.; Bonnart, C.; Descargues, P.; Hovnanian, A.; Gallo, R.L. Kallikrein-mediated proteolysis regulates the antimicrobial effects of cathelicidins in skin. FASEB J. 2006, 20, 2068-2080.

42. Kanada, K.N.; Nakatsuji, T.; Gallo, R.L. Doxycycline Indirectly Inhibits Proteolytic Activation of Tryptic Kallikrein-Related Peptidases and Activation of Cathelicidin. J. Invest. Dermatol. 2012, 132, 1435-1442.

43. Le Poul, E.; Loison, C.; Struyf, S.; Springael, J.Y.; Lannoy, V.; Decobecq, M.E.; Brezillon, S.; Dupriez, V.; Vassart, G.; van Damme, J.; et al. Functional characterization of human receptors for short chain fatty acids and their role in polymorphonuclear cell activation. J. Biol. Chem. 2003, 278, 25481-25489.

44. Maslowski, K.M.; Vieira, A.T.; Ng, A.; Kranich, J.; Sierro, F.; Yu, D.; Schilter, H.C.; Rolph, M.S.; Mackay, F.; Artis, D.; et al. Regulation of inflammatory responses by gut microbiota and chemoattractant receptor GPR43. Nature 2009, 461, 1282-1286.

45. Vaishnavi, C. Established and potential risk factors for Clostridum difficile infection. Indian J. Med. Microbiol. 2009, 27, 289-300.

46. Hing, T.C.; Ho, S.; Shih, D.Q.; Ichikawa, R.; Cheng, M.; Chen, J.; Chen, X.; Law, I.; Najarian, R.; Kelly, C.P.; et al. The antimicrobial peptide cathelicidin modulates Clostridium difficile-associated colitis and toxin A-mediated enteritis in mice. Gut 2012, 62, 1295-1305.

47. Giesemann, T.; Guttenberg, G.; Aktories, K. Human alpha-defensins inhibit Clostridium difficile toxin B. Gastroenterology 2008, 134, 2049-2058.

48. Brandl, K.; Plitas, G.; Mihu, C.N.; Ubeda, C.; Jia, T.; Fleisher, M.; Schnabl, B.; DeMatteo, R.P.; Pamer, E.G. Vancomycin-resistant enterococci exploit antibiotic-induced innate immune deficits. Nature 2008, 455, 804-807.

49. Yoshio, H.; Tollin, M.; Gudmundsson, G.H.; Lagercrantz, H.; Jornvall, H.; Marchini, G.; Agerberth, B. Antimicrobial polypeptides of human vernix caseosa and amniotic fluid: Implications for newborn innate defense. Pediatr. Res. 2003, 53, 211-216. 
50. Lee, A.Y.; Paweletz, C.P.; Pollock, R.M.; Settlage, R.E.; Cruz, J.C.; Secrist, J.P.; Miller, T.A.; Stanton, M.G.; Kral, A.M.; Ozerova, N.D.; et al. Quantitative analysis of histone deacetylase-1 selective histone modifications by differential mass spectrometry. J. Proteome. Res. 2008, 7 , 5177-5186.

51. Cunnane, G.; Bjork, L.; Ulfgren, A.K.; Lindblad, S.; FitzGerald, O.; Bresnihan, B.; Andersson, U. Quantitative analysis of synovial membrane inflammation: A comparison between automated and conventional microscopic measurements. Ann. Rheum. Dis. 1999, 58, 493-499.

(C) 2014 by the authors; licensee MDPI, Basel, Switzerland. This article is an open access article distributed under the terms and conditions of the Creative Commons Attribution license (http://creativecommons.org/licenses/by/3.0/). 